\title{
Endoscopic GIST resection using FlushKnife ESD and subsequent perforation closure by means of endoscopic full-thickness suturing
}

Gastrointestinal stromal tumors (GIST) are the most common mesenchymal tumors of the gastrointestinal tract. It has been debated whether the morbidity and mortality associated with surgery are acceptable when removing these lesions, which have a low potential for malignancy. Endoscopic submucosal dissection (ESD) enables en-bloc resection of such lesions regardless of their size and shape. However, ESD is associated with a risk of perforation of up to $5 \%$, depending on the size and location of the lesion. In order to maintain better visualization during ESD, the Fujinon FlushKnife (Fujinon, Willich, Germany) has been recently developed [1-3].

The case presented here involved a 58year-old man with a gastric GIST ( $\bullet$ Fig. 1). Tumor resection was performed by means of FlushKnife ESD ( Fig. 2) following submucosal injection of $30 \mathrm{ml}$ saline containing epinephrine $1: 10000$. GIST enucleation was performed endoscopically within 32 minutes. After ESD it became obvious that the gastric wall had been perforated, with air leakage and visible abdominal distension. Endoscopic full-thickness suturing of the perforation site was attempted to avoid surgical intervention ( $\bullet$ Fig. 3 and 4, Video 1). The endoscopic suturing time was 12 minutes and an adequate suturing result was confirmed endoscopically. Enteral feeding was reestablished within 48 hours, and control gastroscopy at 72 hours after treatment confirmed complete closure of the perforation before the patient was discharged ( $\bullet$ Fig. 5 and $\mathbf{6}$ ).

The NDO Plicator device (NDO Surgical Inc., Mansfield, Massachusetts, USA), which enables endoscopic transmural suturing, was initially developed for the treatment of gastroesophageal reflux disease. Limited experience of using this device for closure of gastrointestinal wall defects has been reported elsewhere [4$6]$. The resultant sealing is composed of the edges of the former defect bound with a nonabsorbable, pledgeted transmural suture ( $\bullet$ Fig. 4). A negative aspect

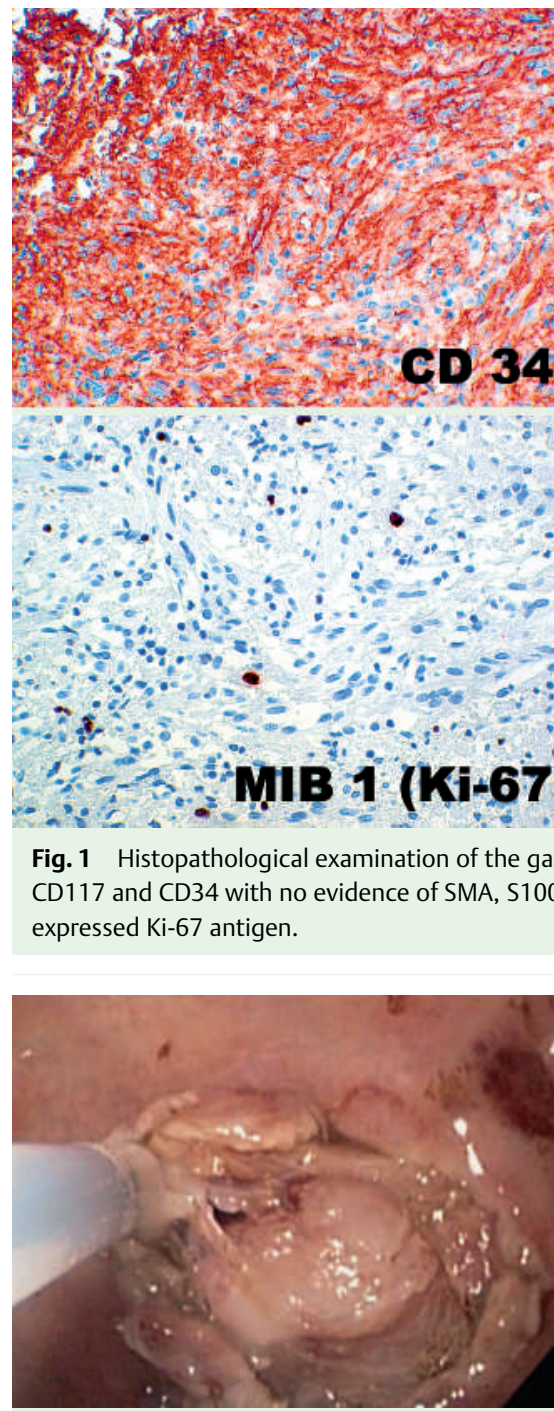

Fig. 2 GIST enucleation using the FlushKnife.

of the transmural procedure is the risk of blindly incorporating or damaging adjacent organs. In addition, the risk of fistulation and migration of the nonresorbable pledgeted sutures is unknown at present. Nevertheless, the Plicator might be a useful endoscopic suturing device allowing surgical intervention to be avoided if perforation occurs.

Endoscopy_UCTN_Code_CPL_1AH_2AZ

Endoscopy_UCTN_Code_CCL_1AB_2AD_3AB

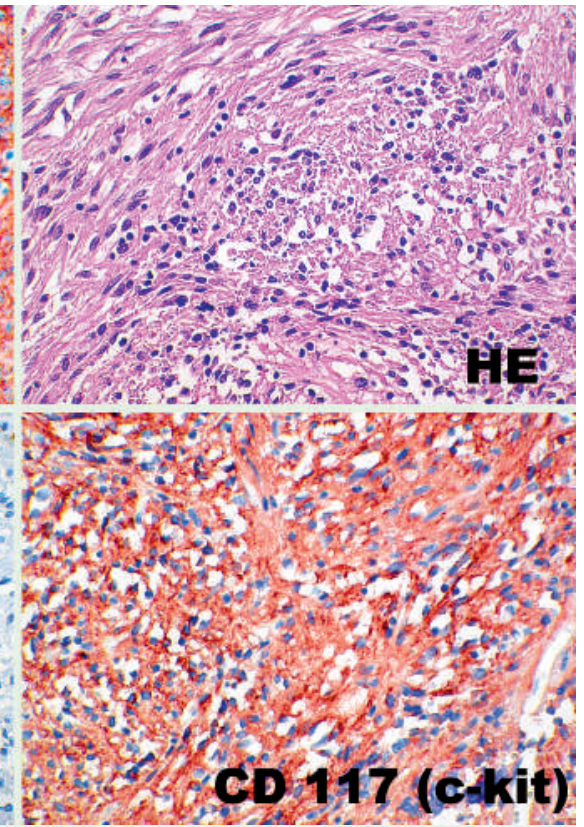

testinal stromal tumor (GIST) was positive for

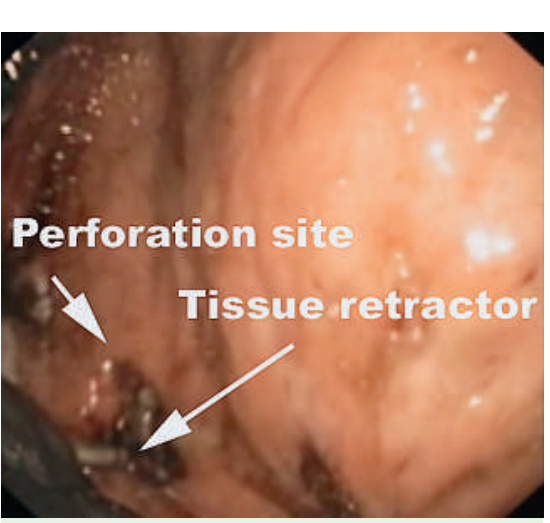

Fig. 3 Perforation closure by means of endoscopic full-thickness suturing. The Plicator is advanced to the perforation site and the retractor is positioned at the border of the lesion.

Video 1

Perforation closure by means of endoscopic full-thickness suturing. 

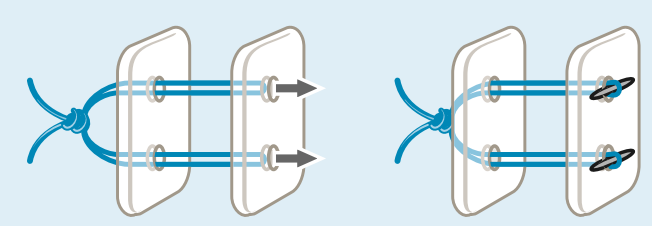

Fig. 4 The endoscopic full-thickness suture.

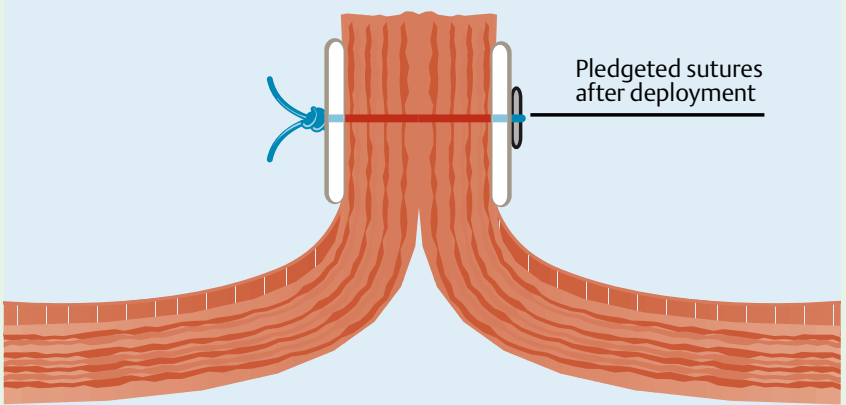

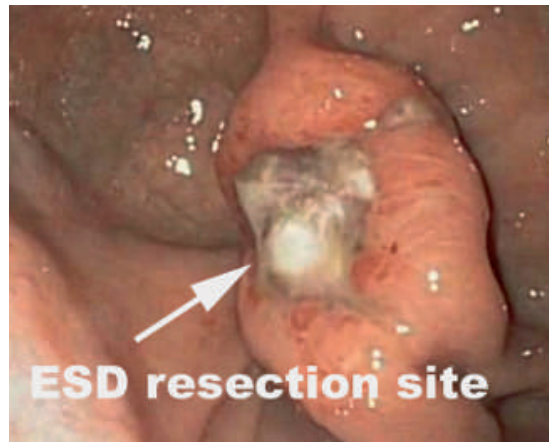

Fig. 5 The ESD resection site is inspected 72 hours after treatment.

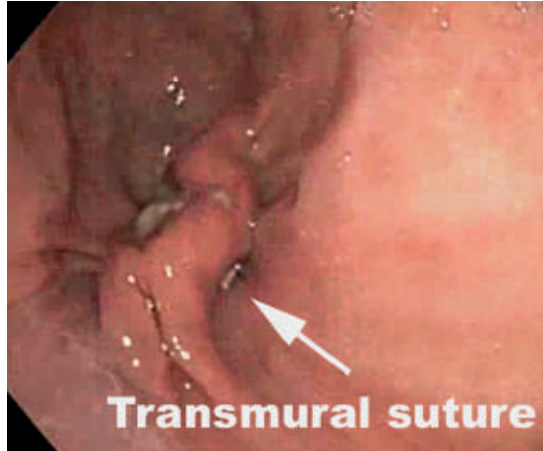

Fig. 6 The transmural sutures closing the gastric wall perforation are inspected 72 hours after treatment.
D. von Renteln ${ }^{1}$, B. Riecken ${ }^{1}$, B. Walz ${ }^{1}$,

H. Muehleisen ${ }^{2}$, K. Caca ${ }^{1}$

1 Department of Gastroenterology, Hepatology and Oncology, Klinikum Ludwigsburg, Ludwigsburg, Germany

2 Department of Pathology, Klinikum Ludwigsburg, Ludwigsburg, Germany

\section{References}

1 Hwang JH, Rulyak SD, Kimmey MB. American Gastroenterological Association Institute technical review on the management of gastric subepithelial masses. Gastroenterology 2006; 7: 2217-2228

2 Imagawa A, Okada H, Kawahara Y et al. Endoscopic submucosal dissection for early gastric cancer: results and degrees of technical difficulty as well as success. Endoscopy 2006; 38: $987-990$

3 Toyonaga T, Nishino E. Effectiveness of endoscopic submucosal dissection using flush knife for esophageal cancers. Gastrointest Endosc 2007; 65: AB93

4 Renteln D von, Schmidt A, Riecken B, Caca K. Gastric full-thickness suturing during endoscopic mucosal resection and for treatment of gastric wall defects. Gastrointest Endosc 2008; 67: 738 - 744

5 Renteln D von, Kaehler G, Eickhoff A et al. Gastric full-thickness suturing following NOTES procedures for closure of the access site to the peritoneal cavity. Endoscopy 2008; 40: E1 -E2

6 McGee MF, Marks JM, Jin J et al. Complete endoscopic closure of gastric defects using a full-thickness tissue plicating device. J Gastrointest Surg 2008; 12: $38-45$

\section{Bibliography}

DOI $10.1055 / \mathrm{s}-2008-1077458$

Endoscopy 2008; 40: E224-E225

(c) Georg Thieme Verlag KG Stuttgart · New York . ISSN 0013-726X

Corresponding author

D. von Renteln, MD

Department of Gastroenterology, Hepatology and Oncology

Klinikum Ludwigsburg

Teaching Hospital of the University of Heidelberg Ludwigsburg

Germany

Fax: +49-7141-9967219

renteln@gmx.net 